\title{
STUDENT UND POLITIK E AS ORIGENS DA SEGUNDA GERAÇÃO DA TEORIA CRÍTICA: HABERMAS E O DIAGNÓSTICO DO CAPITALISMO TARDIO NOS ANOS 60's ${ }^{1}$
}

Leonardo da Hora Pereira (Univeristé Paris Ouest) ${ }^{2}$ leonardojorgehp@gmail.com

Resumo: Neste artigo, pretendemos mostrar como o projeto intelectual de Habermas começa a se estruturar desde o seu primeiro livro (Student und Politik de 1961). Nesta obra, já aparecem nítidas diferenças em relação à primeira geração da Teoria Critica, notadamente quando se trata do diagnóstico do capitalismo tardio. Com isso, esperamos resgatar a importância da obra e do tema para a compreensão do percurso teórico do autor. Por outro lado, neste momento Habermas ainda mantém uma postura de critica radical da ordem capitalista, algo que será claramente revisado nas obras de maturidade, sobretudo a partir dos anos 80 .

Palavras-chave: Teoria Crítica; Habermas; capitalismo tardio; filosofia social.

\section{INTRODUÇÃO}

Quando se trata de traçar as diferenças entre a primeira e a segunda gerações da Teoria Critica frankfurtiana, não faltam referências para mostrar o quanto o principal representante da segunda geração - Jürgen Habermas - se afasta de algumas das teses fundamentais de seus antecessores (nota-

\footnotetext{
${ }^{1}$ Recebido em: 14-03-2014/Aprovado: 01-11-2014/Publicado on-line: 31-08-2015.

${ }^{2}$ Leonardo da Hora Pereira é Doutorando em Filosofia na Université Paris Ouest Nanterre La défense e pesquisador do laboratorio Sophiapol, Nanterre, France e Bolsista Capes.
} 
damente Horkheimer, Adorno e Marcuse) $)^{3}$. Nesse sentido, ressalta-se por exemplo como a concepção habermasiana de racionalidade se amplia a ponto de abarcar não apenas uma dimensão instrumental, mas também uma dimensão comunicativa, que para além da relação meios-fins abre espaço para procedimentos de discussão livre e igualitária entre sujeitos. Ou ainda, de um modo mais geral, sublinha-se como Habermas realiza a crítica de seus antecessores a fim de mostrar que a Teoria Crítica se encaminhara para um beco sem saída e que o diagnóstico do mundo totalmente administrado perdera seu prazo de validade. Afinal, no cerne do projeto habermasiano reside a tentativa de continuar a enxergar potenciais emancipatórios na modernidade, após o proclamado esgotamento do modelo marxista (aqui, quase sinônimo de produtivista) de emancipação. O lamento pela revolução perdida da primeira geração cederia então lugar à atenção às ambivalências modernas e às conquistas democráticas .

No entanto, apesar da notoriedade desta problemática, alguns temas e/ou obras que marcam o distanciamento habermasiano em relação à primeira geração são bem menos estudados. É interessante notar como a maior parte dos comentadores costuma mencionar apenas as obras de Habermas que datam a partir da década de 70 para demonstrar a mudança de rumo que ele opera na Teoria Critica. Obviamente, nas obras de maturidade, como a Teoria da Ação Comunicativa, o seu projeto aparece de forma mais clara e acabada. Entretanto, acreditamos que desde algumas de suas primeiras publicações, as diferenças entre Habermas e seus antecessores já começam a aparecer. Por outro lado,

\footnotetext{
${ }^{3}$ A esse respeito, podemos mencionar por exemplo Honneth (1999).
} 
não deixa de ser interessante observar como a trajetória habermasiana não constitui uma linha reta, mas antes é feita de inflexões e momentos distintos .

Neste artigo, gostaríamos de propor duas hipóteses interpretativas acerca da trajetória habermasiana. A primeira é que pelo menos desde a introdução que ele escreve para a obra coletiva Student und Politik (Universitários e política) de 1961 e que consta como seu primeiro livro publicado, Habermas já demonstra o quanto sua posição é distinta daquela de Adorno ou Horkheimer acerca das novas tarefas da Teoria Crítica, apesar de alguns traços comuns de diagnóstico. A segunda, que se entrelaça com a primeira, diz respeito a um dos temas privilegiados por Habermas nesta obra para estabelecer tais diferenças: o diagnóstico do capitalismo tardio. A propósito deste ultimo, destaca-se as diferenças de recepção por parte de cada geração em relação aos trabalhos do economista alemão Friedrich Pollock .

Com isso, o nosso objetivo é resgatar a relevância tanto da obra quanto do tema para a compreensão da trajetória intelectual de Habermas. Pois se o texto em questão é muito pouco analisado pelos comentadores ${ }^{4}$, essa temática mais diretamente vinculada a aspectos econômicos e sociais costuma ser negligenciada em favor de temas como esfera pública, democracia deliberativa, racionalidade comunicativa ou ética do discurso, os quais são obviamente importantes dentro do esquema habermasiano, mas que precisam ser compreendidos tendo em conta o seu contexto econômicosocial adequado. Isto é, quando se trata da reiteração dos marcos distintivos da experiência intelectual do filósofo alemão, é importante entender por que tais temas, antes

\footnotetext{
${ }^{4}$ Em relação à literatura brasileira, Pinzani (2009) constitui uma rara exceção.
} 
quase que completamente ausentes do escopo da Teoria Critica, assumem um papel central. E para isso seja talvez produtivo retomar o diagnóstico habermasiano do capitalismo tardio .

No entanto, não pretendemos com isso afirmar que existe uma linha de continuidade pura e simples entre o Habermas de Student und Politik e aquele da Teoria da Ação Comunicativa ou Direito e Democracia. Pelo contrario, como veremos adiante, subsistem diferenças importantes em termos normativos e de posicionamento político. Teremos a oportunidade de constatar que no momento em que Habermas redige o texto de 1961, ele ainda mantém muito do ímpeto anticapitalista que será abandonado progressivamente no curso de sua trajetória .

Para tentar demonstrar a plausibilidade das hipóteses propostas acima, procederemos da seguinte forma. Num primeiro momento, mostraremos brevemente como um novo diagnóstico do capitalismo (tardio) trazido por Friedrich Pollock influencia a primeira geração. Num segundo momento, analisaremos, a partir de Student und Politik, como Habermas absorve diferentemente o trabalho de Pollock e sobretudo como ele já esboça aí um diagnóstico do capitalismo tardio que lhe permite enxergar novos potenciais emancipatórios assim como traçar novas tarefas para a Teoria Critica .

\section{OS ANTECEDENTES DE HABERMAS NO CAMPO CRÍTICO: POLLOCK, ADORNO E HORKHEIMER EM TORNO DA NOÇÃO DE CAPITALISMO DE ESTADO}

A nossa tarefa é então a de compreender em que os diagnósticos de Adorno/Horkheimer e de Habermas acerca do 
capitalismo tardio diferem um do outro. Ou melhor, dado que as teses de Pollock exerceram forte impacto nas formulações tanto de Adorno/Horkheimer quanto de Habermas acerca do capitalismo tardio, seria importante entender como cada geração as recepciona e as integra nos seus modelos críticos. Não poderemos aqui analisar detalhadamente os diversos diagnósticos produzidos pela primeira geração (NOBRE 2008). No entanto, retomaremos brevemente as teses de Pollock sobre o "capitalismo de Estado" assim como o modo pelo qual elas são apropriadas por Adorno e Horkheimer, para finalmente passar para o diagnóstico habermasiano na seção seguinte .

No texto "State Capitalism: Its Possibilities and Limitations", Pollock sintetiza as suas análises acerca das transformações sofridas pelos países altamente industrializados desde o fim da Primeira Guerra Mundial. Basicamente, a abordagem visa a captar o tipo de transformação que o capitalismo privado (já em sua fase monopolista) sofre em resposta às crises sistêmicas e ao desemprego estrutural. Assim, a obra de Pollock "parte exatamente da capacidade de regeneração do capitalismo” (RUGSTIKY 2008, p. 63), em que a perspectiva marxista clássica do colapso é abandonada

Segundo Pollock, essa nova fase do capitalismo se notabiliza por pelo menos três aspectos. Os dois primeiros são:

1. O mercado perdeu sua função de controle do equilíbrio entre produção e distribuição. Esta função foi assumida por um sistema de controles diretos. A liberdade de comércio, de empresa e de trabalho está submetida às intervenções do governo em um tão alto grau que ela foi a bem dizer abolida. Junto com o mercado autônomo, desaparecem as assim chamadas leis econômicas.

2. Estes controles são transferidos para o estado, que utiliza uma combinação de antigos e novos meios, entre os quais um assim cha- 
mado 'pseudo-mercado ', para a regulação e expansão da produção e sua equiparação com o consumo (POLLOCK 1978, p. 73).

A partir destes dois elementos, já se pode observar que o capitalismo se reorganiza de forma planificada, em que o Estado é o maior capitalista. A substituição do mercado pelo Estado da função de coordenador da produção e da distribuição se estruturaria concretamente em torno de cinco elementos ${ }^{5}$. Primeiro, o Estado elaboraria um plano geral que dirigiria a produção, a distribuição, a poupança e o investimento. Em segundo lugar, todos os preços seriam administrados em função do plano e não poderiam flutuar livremente. Terceiro, até mesmo o lucro, mesmo ainda exercendo um papel importante, seria subordinado ao plano, não podendo contradizer os objetivos deste. Quarto, ocorreria uma racionalização vigorosa no quadro das ações estatais, substituindo toda improvisação. Por fim, os meios econômicos seriam substituídos fundamentalmente por meios políticos como última garantia da reprodução da vida econômica.

De um modo geral, toda essa estrutura vem para cumprir com dois objetivos básicos: "garantir o pleno emprego e manter os elementos básicos da antiga estrutura social" (POLLOCK 1978, p. 74).

Por outro lado, o terceiro aspecto que caracteriza o capitalismo de Estado introduz uma distinção importante no modelo proposto por Pollock:

Sob a forma totalitária de capitalismo de estado, o estado é o instrumento de poder do novo grupo dirigente, o qual resultou da fusão dos interesses mais poderosos, o pessoal do alto-escalão da gestão industrial e de negócios, os estratos mais elevados da burocracia esta-

\footnotetext{
${ }^{5}$ No que se segue, adotamos o esquema proposto por Rugstky (2008).
} 
tal (incluindo o militar), e as principais figuras da burocracia do partido vitorioso. Todos os que não pertencem a este grupo são mero objeto de dominação .

Sob a forma democrática do capitalismo de estado, o estado tem as mesmas funções de controle mas é ele mesmo controlado pelo povo (POLLOCK 1978, pp. 73-4).

No entanto, seja na sua forma totalitária ou democrática, entre as principais consequências do desenvolvimento do capitalismo de Estado, temos a estabilização do capitalismo e o afastamento da possibilidade de colapso sistêmico, de modo que esse não funcionaria mais de modo "contraditório", sem sofrer mais a ameaça de crises e sem indicar quaisquer possibilidades internas de ruptura que abrissem espaço para uma superação em direção ao socialismo. Ademais, haveria uma neutralização do conflito entre capital e trabalho - na forma totalitária, com o completo domínio "espiritual" das massas e com o foco mantido no "inimigo externo"; e na sua forma democrática, com todas as garantias do Welfare State .

Além disso, algo que marcaria uma profunda mudança na natureza do capitalismo e um grande rompimento com a teoria de Marx seria o fato de que o conjunto do sistema econômico e social passaria a ser dirigido de modo racional e consciente, sem que isso implicasse a passagem para o socialismo. Segundo Pollock, “(...) [a questão de] quais necessidades devem ser satisfeitas, e como, não é deixada para o âmbito anônimo e inconsciente do mercado, realizada post festum, mas para uma decisão consciente acerca dos fins e dos meios, ao menos em linhas gerais e antes que a produção se inicie" (POLLOCK 1978, p. 75). Como observa Nobre (1998, p. 24), “isto é justamente o que não pode de modo algum ser conciliado com a letra do texto de Marx, 
pois significa alterar o próprio conceito de capitalismo sobre o qual repousa a teoria” e, acrescentamos, é justamente esta racionalidade que atua sobre o conjunto da estrutura de produção, distribuição e consumo que elimina o caráter contraditório do capitalismo. Não à toa, Pollock chega mesmo a afirmar que "(...) sob o capitalismo de Estado, a economia política perdeu o seu objeto. Não existem mais problemas econômicos no velho sentido, se a equiparação de todas as atividades econômicas não é mais alcançada por meio das leis naturais de mercado, mas através do planejamento consciente. Onde antes o economista quebrava a cabeça com o inimigo do processo de troca, ele só encontra sob o capitalismo de estado problemas administrativos"(POLLOCK 1978, p. 86).

Isso abre espaço para o que talvez seja a maior consequência introduzida pelo modelo do capitalismo de Estado, a saber , a primazia da política sobre a economia, ou, nas palavras do autor, "isso significa a transição de uma era predominantemente econômica para uma predominantemente política” (POLLOCK 1976, p. 76). Em comparação à teoria marxista, temos então que a política deixa de ser um fenômeno superestrutural.

Do ponto de vista da história da Teoria Crítica, esse último elemento tem uma importância seminal. Já em Pollock, o foco do prognóstico e da identificação dos obstáculos à emancipação social muda sensivelmente. Enquanto a perspectiva de superação do capitalismo some do horizonte, delineia-se uma estratégia de luta política em vista do controle político do Estado e junto com a intenção de institucionalização de valores democráticos. $\mathrm{O}$ centro das preocupações deixa de ser a revolução das relações de produção capitalistas; o que resta é a expectativa de que as 
formas democráticas vençam a batalha contra as formas totalitárias de capitalismo de Estado, numa análise que deixa de considerar que exista ainda alguma dinâmica propriamente econômica do capitalismo, para apreender a sua dinâmica política (RUGSTIKY 2008, p. 69) .

Assim, no último tópico de seu artigo, ao discutir as implicações políticas do capitalismo de estado, Pollock afirma que "se o Estado se torna o controlador onipotente de todas as atividades humanas, a questão de quem controla o controlador abarca o problema de se o capitalismo de estado abre uma nova via para a liberdade ou conduz à sua perda na medida em que a esmagadora maioria é concernida... Tudo depende de quais grupos em ultima analise dirigem as decisões de um governo cujo poder em todos os assuntos - econômicos e não econômicos - nunca foi ultrapassado na história moderna" (POLLOCK 1978, p. 89) .

Pollock conclui afirmando que "é de vital importância para todos que acreditam nos valores da democracia que uma investigação seja feita de se o capitalismo de Estado pode ser tomado sob o controle democrático. O problema social assim como moral com o qual as democracias são confrontadas foi formulado como segue: "Como nós podemos fazer um uso eficiente de nossos recursos, e entretanto, ao mesmo tempo, preservar valores subjacentes em nossa tradição de liberdade e de democracia?" (POLLOCK 1978, p. 92).

Como se vê, Pollock identifica aspectos positivos na reestruturação burguesa do pós-guerra. Para ele, o capitalismo de Estado democrático poderia levar a um aproveitamento mais racional e efetivo dos recursos disponíveis, e produzir uma elevação geral do nível de vida. Nessa perspectiva, e retomando a tese da primazia da política, as suas últimas pa- 
lavras afirmam que "Os principais obstáculos à forma democrática do capitalismo de Estado são de natureza política e só podem ser superados politicamente. Se nossa tese se mostrar correta, então a sociedade em seu nível atual pode superar as barreiras do sistema de mercado através do planejamento econômico. Alguns dos melhores pensadores estudam a questão de como tal planejamento pode ser feito de modo democrático, mas muito trabalho teórico ainda terá de ser realizado até que a questão encontre sua resposta” (POLLOCK 1978, p. 92).

Os escritos de Pollock da década de 40, principalmente o artigo analisado acima, tiveram um impacto imediato sobre o "círculo interno" da "Escola de Frankfurt". Não à toa, o célebre livro escrito por Horkheimer e Adorno, Dialética do Esclarecimento, foi dedicado ao economista alemão. Neste livro, o diagnóstico é o de um bloqueio estrutural da práxis transformadora, e isso muito deve à ideia de que o capitalismo de Estado (referido, no livro, como "capitalismo administrado", "mundo administrado" ou "capitalismo tardio") não apresenta mais elementos internos contraditórios e, desse modo, deixa de apontar para além de si mesmo - o que contrariava fortemente as teses de Marx. No entanto, Adorno e Horkheimer não absorveram sem mais a tese de Pollock, pois "apesar de concordarem, de maneira geral, com a ideia de Pollock de uma nova forma de primazia da política, não concordaram com ele em que o capitalismo de Estado tivesse potencial para assumir uma forma democrática, fundada em algum tipo de controle popular. Na Dialética do esclarecimento, o que se encontra é o mundo administrado, uma forma sofisticada de controle social de que as massas estão inteiramente excluídas e sobre a qual não têm qualquer tipo de domínio" (NOBRE 2008, p. 47). 
Os trabalhos de Pollock também tiveram como consequência fundamental o fato de Adorno e Horkheimer não mais considerarem a economia política como a disciplina organizadora do modelo crítico .

Por outro lado, talvez a ideia de fundo presente na Dialética do esclarecimento, que determina o diagnóstico de época e orienta as investigações de amplo espectro sobre a razão humana, que constituem o conteúdo propriamente dito do livro, seja que o sistema econômico do capitalismo administrado é controlado de fora, politicamente, e no entanto, esse controle político não é exercido de maneira transparente. Esse controle é exercido burocraticamente, segundo a racionalidade própria da burocracia. Essa racionalidade chamase, na linguagem de Horkheimer, "instrumental": trata-se de uma racionalidade que pondera, calcula e ajusta os melhores meios a fins dados exteriormente aos agentes (NOBRE 2008, p. 48). Acresce que, ainda que o modelo de um tal controle social possa ter sido retirado da forma totalitária de capitalismo de Estado, Adorno e Horkheimer, ao contrário de Pollock, estende este processo de dominação (não sem nuances, mas sem modificações substanciais) mesmo para a sua forma democrática, que em 1947 era visto apenas como um "elemento perturbador" do diagnóstico mais amplo (NOBRE 1998, p. 32).

De todo modo, na Dialética do esclarecimento de Adorno e Horkheimer $(1997)^{6}$, a tese da primazia da política seria percebida apenas pelo seu aspecto negativo, no quadro da realidade do capitalismo tardio, "a regulação estatal implicaria uma densa malha de normas jurídicas e de intervenções administrativas que recobririam crescentemente $o$

\footnotetext{
${ }^{6}$ Ver também ADORNO (1997).
} 
cotidiano das pessoas. Não seria por acaso que o poder administrativo foi caracterizado por muitos como um instrumento de normatização forçada, de vigilância e, no limite, brutalidade reificante. Por essa razão, a crítica de Marx à exploração material e ao empobrecimento precisaria ser deslocada às deformações de uma sociedade administrada, controlada e protegida" (MELO 2009, p. 126) .

E Habermas, como lida com esse fenômeno a partir da recepção das teses de Pollock? Poder-se-ia responder à esta questão mostrando que Habermas já parte da estabilização do capitalismo de Estado democrático, enquanto que Horkheimer e Adorno permanecem vinculados à sua forma autoritária, de sorte que eles veem o Estado de direito como um elemento perturbador de seu diagnóstico mais geral acerca da sociedade administrada (NOBRE 1998, p. 47; HONNETH 1986, p. 109). Isto é, Habermas procura explorar as ambiguidades e tensões ligadas a um fato que se torna bastante explícito no pós-guerra: as relações de produção não apenas foram repolitizadas em virtude do intervencionismo estatal, mas o capitalismo se tornou compatível com uma democracia de massas e com um programa de bem-estar para os seus trabalhadores. A partir desse momento, não apenas a ideia de uma crise sistêmica da economia capitalista e de uma revolução proletária sai do horizonte, mas também a de um mundo totalmente administrado, sem falhas. Há contradições e zonas de conflito no capitalismo tardio, e estas aparecem cada vez mais em torno da noção de democratização efetiva. Vejamos então, de modo um pouco mais detalhado, como esse diagnóstico habermasiano começa a se constituir em Student und Politik. 


\section{AS ORIGENS DE UMA NOVA PROBLEMÁTICA PARA A TEORIA CRÍTICA DA SOCIEDADE EM STUDENT UND POLITIK (1961)}

Gostaríamos de tentar mostrar que desde o seu primeiro livro publicado, Student und Politik (Universitários e política), Habermas não apenas se ocupava da elaboração de um diagnóstico do capitalismo avançado (que aqui aparece principalmente sob o signo do conceito de Sozialstaat), mas também definia as tarefas de uma nova Teoria Crítica da Sociedade a partir deste diagnóstico.

Com efeito, Student und Politik corresponde à sistematização de um estudo empírico coletivo para o qual Habermas escrevera, já em 1958 (HABERMAS 1973, p. 9), uma introdução de natureza mais teórica e abrangente. Logo no começo do texto, ele já põe a questão da justificação de uma pesquisa acerca da participação política dos estudantes. A participação política seria um valor em si? Ao longo da introdução, Habermas tenta mostrar por que o problema da participação política ganhou uma importância significativa no panorama contemporâneo, a ponto de merecer uma teorização específica por parte da Teoria Crítica; para tanto, ele já esboça um diagnóstico de época. De fato, já em 1961, estava presente em Habermas a intuição central segundo a qual há uma contradição (Widerspruch) entre os fundamentos da legitimação da sociedade burguesa por meio da ideia de democracia e a realidade constitucional do Estado de Direito burguês. Baseando-se em Franz Neumann, Habermas salienta que a ideia de democracia, ao contrário do que propagava a ciência política da época, não é uma forma de Estado como outra qualquer: "Sua essência consiste no fato de que ela engendra mudanças sociais profundas que aumen- 
tam e, no final, talvez produz completamente a liberdade dos homens. A democracia se ocupa da autodeterminação da humanidade, e apenas quando esta for efetiva, aquela será verdadeira. Nesse sentido, a participação política se tornará idêntica à autodeterminação (HABERMAS et. al. 1961, p. 15) .

A ideia de democracia se institucionaliza na medida em que cidadãos maduros, sob as condições de uma atuante esfera pública política, através de uma sensata delegação de suas vontades e do controle eficaz de sua realização, tomam a instituição de sua vida social em suas próprias mãos; com isso, a autoridade pessoal se converte em autoridade racional (HABERMAS et. al. 1961, p. 16) .

Desde essa época, Habermas partilha da convicção segundo a qual as democracias parlamentares do ocidente, até mesmo as pseudo-democracias de regimes autoritários como eram a França e Portugal nesse período, vivem da consciência dos cidadãos, de acordo com a qual a dominação é mediada através de uma autodeterminação racional de homens maduros (HABERMAS et. al. 1961, p. 17). Segundo os seus fundamentos legitimatórios, a sociedade burguesa é um livre jogo de forças iguais; ora, a partir deste modelo, não se pode justificar a dominação política, e ainda menos uma dominação de classe. Ou seja, aqui Habermas já mostra que enxergava na tradição ocidental algo para além do império da razão instrumental. A modernidade, então, trouxe ganhos do ponto de vista normativo com a ideia de que o poder político deve ser baseado em uma autoridade racional, cujo fundamento de legitimação exige o consenso livre e manifesto de todos os cidadãos. Por isso, ele não poderia concordar com uma visão unilateral do processo de modernização, que seria visto apenas como um desdobramento do 
fenômeno da reificação .

Todavia, ainda que o Estado liberal proclame e em certa medida institucionalize a ideia de democracia, ele opera na verdade sobre a base de uma democracia das minorias fundada sobre uma hierarquia social. De acordo com Habermas, apesar da contradição entre a realidade constitucional do Estado de direito burguês e a ideia de democracia, o Estado sempre logrou êxito historicamente na resolução desta contradição em seu próprio espaço (HABERMAS et. al. 1961, p. 17). Não obstante, e aqui já aparece a importância de um diagnóstico do capitalismo tardio, a sua tese é que atualmente, nos países ocidentais mais desenvolvidos, esta contradição se torna cada vez mais aguda ${ }^{7}$ Seguindo a sua tese, só há duas alternativas: ou o Estado liberal evolui para um Estado social e verdadeiramente democrático, ou aquele regride para uma forma de regime autoritário. Assim, onde Adorno e Horkheimer enxergavam um processo mais ou menos consumado de dominação burocrática, Habermas vê uma tensão que se agudiza cada vez mais. Em todo caso, a questão da participação política ganharia apenas função e sentido onde a democracia é entendida como um processo histórico moderno de efetivação. Ora, se a tensão entre a pretensão normativa do fundamento de legitimação e a realidade institucional das democracias burguesas se intensifica, uma pesquisa em torno do tema da participação política, bem como a sua teorização, pode ser justificada. Mas por que há esta intensificação da contradição, de sorte que estas duas alternativas apareçam como as únicas ten-

\footnotetext{
7 "Nas figuras desenvolvidas que o Estado de Direito burguês assume nos países desenvolvidos do mundo ocidental, este aparece entretanto cada vez mais sobrecarregado pela contradição entre o que, segundo a sua Ideia, ele quer ser e o que ele é na realidade " (HABERMAS et. al. 1961, p. 17)
} 
dências possíveis? $\bigcirc$ que mudou, para que a tensão, e por conseguinte, a possibilidade de institucionalização plena da ideia normativa de democracia apareça no horizonte? Aqui entra em cena efetivamente a importância do diagnóstico de época enquanto capitalismo tardio - este deve explicar por que a tensão atualmente é mais aguda e, portanto, em que medida aquele potencial normativo da tradição liberalburguesa teria possibilidade de se institucionalizar sob as atuais condições do sistema capitalista. Isso possibilitaria a enunciação de prognósticos visando a superação dos obstáculos à emancipação. O desafio da teoria é, assim, o de encontrar um ancoramento no real para a emancipação - algo tornado bastante problemático pelo diagnóstico da Dialética do Esclarecimento .

A fim de tornar a sua tese plausível, Habermas se apóia sobre a análise do processo de transformação do Estado liberal em um fiador dos serviços de interesse geral. $O$ pano de fundo da dissolução do capitalismo liberal e da abolição da autonomização da sociedade civil (bürgerliche Gesellschaft) enquanto esfera das relações capitalistas perante o Estado justifica a focalização da descrição sobre as transformações sofridas pelo Estado burguês. A partir do momento em que a reprodução social passa a depender da intervenção deste último, o diagnóstico deve se concentrar na política e não mais na economia - mesmo no interior de uma sociedade que ainda é capitalista. Desta maneira, o essencial do diagnóstico de Habermas pode ser resumido da seguinte forma : desde o momento que a economia de livre concorrência evolui em direção a uma economia organizada, como consequência da concentração de capitais, a democracia parlamentar clássica assume a figura de uma democracia de massas baseada em partidos no poder. Dito de outro modo, 
desde que as esferas da sociedade civil e do Estado em grande medida se interpenetram, a política ganha mais importância e a dependência entre esta e a sociedade civil se torna recíproca (HABERMAS et. al. 1961, p. 51) .

Foi a partir da Primeira Guerra mundial que ocorreu esta transformação essencial na natureza do Estado. Intervenções estatais no sistema de produção e de distribuição se tornaram necessárias. A interdependência entre a esfera do Estado e aquela da sociedade cresceu. O Estado se tornou então um Estado social e a administração (Verwaltung) deixou de ser uma simples guardiã da ordem para começar a assegurar serviços que pertenciam até então à esfera privada. Assim, a reprodução da sociedade não se realiza mais através das puras garantias jurídicas; ela exige agora o equilíbrio trazido pelas intervenções estatais (HABERMAS et. al. 1961, p. 21) .

Além das funções tradicionais executadas pela justiça e pela polícia, o Estado adquire agora novas tarefas: em primeiro lugar, a tarefa de proteção, de indenização e de compensação em relação aos grupos economicamente mais frágeis (operários, inquilinos, clientes, etc.). Em seguida, há a tarefa de evitar ou de atenuar em alguma medida os efeitos causados pelas mudanças estruturais (a política de proteção da classe média), ou de introduzir estas mudanças de maneira planificada (por exemplo, através de intervenções da política social tendo por objetivo uma redistribuição não apenas gradual dos rendimentos). Depois, temos a tarefa de manter em equilíbrio o sistema econômico geral (seja através dos meios da política clássica de conjuntura, seja por intervenções diversificadas, como aquelas que incidem nas decisões acerca dos investimentos). E, finalmente, aparece a tarefa de garantir as prestações públicas dos serviços (para a 
educação, saúde, transporte, etc.) (HABERMAS et. al.1961, p. 22) .

Apesar destas transformações profundas na natureza do Estado tornado intervencionista, a sociedade continua baseada na apropriação privada dos meios de produção sociais. $\mathrm{O}$ processo econômico se regula sempre de acordo com as instituições clássicas do direito privado. Assim, a forma do Estado, que pressupõe essencialmente a separação entre o Estado e a sociedade civil-burguesa, foi mantida, ainda que esta separação não se apresente mais em sua forma antiga e nítida .

Habermas faz a importante constatação de que, ainda que a sociedade civil não se coloque mais diante do Estado enquanto uma entidade independente, esta não se torna tampouco uma sociedade política strictu sensu. Este fenômeno se mostra na divergência entre os poderes jurídicos e os poderes efetivos do Parlamento. Naquilo que diz respeito ao monopólio da legislação, acontece uma polarização entre, de um lado, a administração e, de outro, os partidos. As decisões políticas são tomadas efetivamente por esses dois pólos e também pelas associações que visam fins particulares, tal como os sindicatos. Em relação à integração entre o Estado e a sociedade civil, há então um deslocamento da ênfase do Parlamento em direção à administração e aos partidos. Segundo o diagnóstico de 1961, estas duas instituições se tornaram os mediadores da relação do Estado para a sociedade (administração) e inversamente da relação da sociedade para o Estado (partidos e associações) (HABERMAS et. al. 1961, p. 23). A sociedade civil, que devido a todas as suas novas disposições para com o Estado se torna mais política, continua não-política. $\mathrm{O}$ caráter privado do campo de ação dos partidos e das associações, que é 
completamente isento do controle público, mostra que a forma liberal do Estado de direito é em certo sentido mantida .

Assim, é preciso sublinhar que o fenômeno complementar ao aumento da intervenção estatal na ordem da propriedade e na sociedade civil em geral corresponde ao fato de que as decisões que eram tomadas antes de maneira não-pública por grupos dominantes, devem determinar hoje imediatamente a esfera política. Em outras palavras, as medida tomadas pelo Estado intervencionista sofrem a influência dos interesses de grupos particulares dominantes, de sorte que o poder social e econômico é atualmente eo ipso político .

A tese de Habermas mostra que a forma do Estado de direito burguês entra em conflito com as condições sociais que não correspondem a ela. Trata-se aí da expressão de uma situação na qual, de um lado, as pressuposições de uma sociedade política que conseguiu conciliar homme e citoyen ou sociedade e Estado se tornaram efetivas, na medida em que há doravante um tipo de primazia da política sobre a economia. De outro lado, a realidade mesma desta sociedade não permite que se disponha do poder social de uma ordem politicamente relevante, já que ela permanece privada, sem controle público ou democrático efetivo. O paradoxo pode finalmente ser enunciado: "Cidadãos apolíticos são produzidos em uma sociedade em si política" (HABERMAS et. al. 1961, p. 24) .

Segundo Habermas, a neutralização do Estado burguês vai ao encontro da nova autonomia que a administração, os partidos e as associações ganharam em face do povo e de seus representantes parlamentares (HABERMAS et. al. 1961, p. 24).. Isso foi necessário porque agora o poder polí- 
tico adquire uma importância que na época do capitalismo liberal ele não tinha. Se a sociedade se torna política, a política, enquanto administração, precisa ser protegida da participação popular em função de continuar assegurando a apropriação privada dos meios de produção. Os grupos dominantes, nas figuras dos partidos de massa e das associações, influenciam decisivamente a administração. Por outro lado, cidadãos apolíticos são produzidos no interior dessa sociedade repolitizada mas fortemente administrada - isto é, Adorno e Horkheimer estavam parcialmente corretos .

Com efeito, a identidade plebiscitário-democrática entre a vontade das respectivas maioridades dos partidos no governo e no parlamento e a vontade do povo é em realidade uma identificação fictícia. Ela se constitui sobre a base daquele que dispõe dos meios de coerção e de educação que permitem a formação e, sobretudo, a manipulação da vontade popular. Os partidos são instrumentos da formação da vontade; entretanto, eles não estão sob o controle do povo, mas antes sob o controle daqueles que dominam o aparato do partido .

Por outro lado, Habermas já esboça aqui uma ideia que será aprofundada em sua obra de 1962, Mudança estrutural da esfera pública : a esfera pública (Öffentlichkeit), que foi um espaço de discussão racional, perdeu sua transparência e sua clareza. Ela se tornou um lugar de manipulação pelos meios de comunicação de massa; em suma, ela foi privatizada. Isso permitiu uma neutralização progressiva da participação política dos cidadãos (HABERMAS et. al. 1961, p. 32), o que passa a ser decisivo numa sociedade cujo Estado não se limita mais a ser um mero garantidor jurídico e policial da ordem de direito privado burguês .

Esta tese não deixa de apresentar ressonâncias do diag- 
nóstico formulado por Adorno e Horkheimer na Dialética do Esclarecimento (PINZANI 2009, p. 42), sobretudo quando ele afirma que o cidadão se torna mero consumidor, destacando o papel de manipulação da mídia ao apresentar noticiais sobre acontecimentos políticos no formato de entretenimento. A informação política se torna uma mercadoria, nem mesmo a propaganda eleitoral se diferencia da comercial (HABERMAS et. al. 1961, p. 48) .

A posição política dos cidadãos nesta sociedade do capitalismo tardio foi determinada por seu contato prolongado com o Estado em setores que pertenciam anteriormente à esfera privada. Este contato com o Estado só ocorreu no campo da administração. Isto é, ele foi essencialmente apolítico, se tomarmos aqui o conceito de político como semelhante ao de uma participação popular efetiva na formação da vontade política. A relação entre os beneficiários (Leistungsempfänger) e o Estado não foi de forma alguma a de uma participação política cujo objetivo fosse fazer prevalecer as decisões deles, mas antes uma relação de exigência abstrata e difusa correlacionada à uma expectativa de abastecimento e compensação (HABERMAS et. al. 1961, p. 32). O cidadão se transforma em um mero cliente do Estado social.

Aqui aparece pela primeira vez uma ideia que acompanhará por muito tempo o pensamento de Habermas e será constantemente aprofundada e desenvolvida. A contradição entre a ideia de democracia e sua institucionalização deixa de ser expressa pela desigualdade de chances de realização dos direitos de igualdade política entre os proprietários e os não-proprietários. Agora, com a relativização do antagonismo explícito de classe, o conteúdo desta contradição também muda: ela aparece doravante como uma despolitização 
das massas paradoxalmente no quadro de uma politização progressiva da própria sociedade ${ }^{8}$. Na medida em que a separação entre o Estado e a sociedade civil é ultrapassada e o poder social se torna imediatamente político, cresce objetivamente a desproporção entre a igualdade jurídica e a desigualdade real na distribuição das chances de participação política no governo. Por isso a contradição constitutiva do Estado burguês se torna mais aguda no contexto de um capitalismo tardio marcado pela repolitização das relações de produção via intervencionismo estatal .

Por outro lado, ainda que o diagnóstico seja o de que a participação política das massas se resuma ao momento do voto, e de que o parlamento perdeu importância em relação à administração, o povo ainda é juridicamente soberano distinção sutil porém fundamental para diferenciarmos a análise habermasiana daquela de Adorno e Horkheimer. Por isso, coloca-se a questão de saber se, naquele momento, uma autêntica participação cidadã na vida política, mesmo que ainda não efetiva, é possível. Ora, segundo Habermas, uma participação política eficaz da massa de cidadãos tem como pré-condição para a sua viabilidade uma certa autonomia da esfera política. Onde os movimentos políticos forem meros reflexos dos movimentos econômicos, uma investigação em torno do sujeito e de seu potencial democrático não apenas seria supérflua, como também sem sentido. Mas aqui entra a importância do diagnóstico do capitalismo tardio para a configuração do modelo haberma-

\footnotetext{
8 "Com o recuo do antagonismo de classe aberto, a contradição alterou sua figura : ela aparece agora como uma despolitização das massas via politização progressiva da sociedade enquanto tal. $\mathrm{Na}$ medida em que a separação entre Estado e sociedade desaparece e o poder social se torna imediatamente político, cresce objetivamente a antiga desproporção entre a igualdade assegurada juridicamente e a desigualdade real na distribuição das oportunidades de participação política ativa" (HABERMAS et. al. 1961, p. 34).
} 
siano de uma nova Teoria Crítica: como vimos, nas sociedades tardo-capitalistas com alto nível de desenvolvimento das forças produtivas, o poder político enquanto tal, com uma certa independência em relação ao poder econômico, se concentrou (HABERMAS et. al. 1961, p. 49). A política não é mais um fenômeno superestrutural e ganhou influência no processo social .

Neste contexto de certa primazia da política, ganha sentido a elaboração de uma teorização acerca da participação política. Se antes a economia era a principal zona de conflito, expressa através da oposição entre capital e trabalho, o Estado ganha centralidade sob as condições do capitalismo tardio e, com isso, a zona de conflito tende também a se deslocar para a questão das chances de participação na codeterminação das decisões tomadas pelo poder político Habermas enxerga portanto uma tensão e um potencial emancipatório no capitalismo tardio de extração democrática, se afastando neste ponto de seus antecessores. No entanto, é importante insistir que esse deslocamento não significa o abandono imediato da crítica do capitalismo. Pelo contrário, apesar de neutralizado, o conflito entre capital e trabalho, o imperativo de valorização, se transfere para o âmbito das prioridades do Estado nas suas decisões políticas, o que gera a necessidade de bloquear a participação política das massas - o conflito capital $\mathrm{x}$ trabalho se transfigura num conflito "capital x democracia". Por isso, os grupos dominantes pressionam no sentido de uma manipulação da esfera pública e de uma despolitização das massas. Uma Teoria Crítica do presente, sempre baseada em diagnósticos de época, deve também ser reformulada em torno da questão da participação política dos cidadãos (que passa a ser vista como o principal caminho para a 
emancipação), uma vez que o poder social se torna imediatamente político. A partir de agora, faz todo o sentido investigar as possibilidades de institucionalização plena da ideia de democracia .

Doravante o alvo essencial da Teoria Critica se desloca para a despolitização das massas e para o clientelismo. $\mathrm{O}$ objetivo é o de realizar plenamente a ideia de democracia já contida, à maneira de Hegel, no núcleo das instituições liberais por meio da constituição de uma sociedade composta de cidadãos maduros e autônomos, que participem da formação da vontade política .

Todavia, Habermas também reconhece que, nas atuais circunstâncias, conceber um controle efetivo das instituições parlamentares por meio de um povo maduro é algo problemático. $\mathrm{O}$ parlamento perdeu importância em face de atores políticos extraparlamentares que conseguem exercer uma pressão eficaz sobre os órgãos estatais. De um lado, temos os membros de organizações de massa, como os sindicatos. De outro, as elites funcionais (tais como managers, altos funcionários e executivos, e especialistas dos altos órgãos da indústria e da administração), que dispõem do aparato burocrático privado e estatal. Ainda que os primeiros possam contribuir para a democratização da sociedade, estas últimas travam esse processo. Por isso, seria necessário elaborar prognósticos que apontem para a confrontação de suas atividades. Ora, se pelo menos na Alemanha tais elites são recrutadas nas fileiras do mundo acadêmico, faz-se necessário investigar, naquilo que diz respeito ao desenvolvimento futuro dessas elites, um campo fundamental de recrutamento destas, qual seja, o estrato dos estudantes universitários (HABERMAS et. al. 1961, p. 53). E neles reside a aposta de Habermas neste momento. Para o autor 
alemão, estes últimos apresentam um potencial para contribuir no processo de democratização e de dissolução da dominação de classe, uma vez que as elites se tornam cada vez mais acadêmicas, e a formação acadêmica deixa de ser progressivamente acesso exclusivo dos privilegiados socialmente. Os estudantes são crescentemente recrutados entre as classes mais populares e podem ter acesso às elites funcionais e dirigentes graças à sua formação (HABERMAS et. al. 1961, p. 53). Por isso, é de se esperar mudanças na consciência política dos estudantes, futuros membros das elites funcionais. É a fim de tentar encontrar um ancoramento no real para esta ideia que Habermas e seus colaboradores empreendem uma pesquisa empírica sobre a consciência política dos estudantes da cidade de Frankfurt (cuja sistematização deu origem ao livro de 61) .

Não obstante, em 1961, Habermas associa o processo de democratização da sociedade com a pretensão de suprimir a dominação de classe e a apropriação privada dos meios de produção (HABERMAS et. al. 1961, p. 55) - e isto se tornaria agora possível via controle democrático do Estado, e não mais pela revolução, já que a política não é mais superestrutural e o Estado adquiriu centralidade na determinação do processo social. Em outras palavras, uma teoria da democracia social plena está aqui intimamente vinculada a uma perspectiva de superação do sistema capitalista de organização social. Para o jovem Habermas, uma sociedade livre significa uma sociedade que utiliza suas forças produtivas materiais e espirituais em proveito da liberação das necessidades, e não apenas em função de interesses privados; politicamente, isso se traduz em uma autoridade ra- 
cional sob o controle de todos os indivíduos 9 . Isto é, ele quer realizar o objetivo clássico do jovem Marx através de uma radicalização da ideia de democracia no seio das instituições liberais ${ }^{10}$, e não mais por meio de uma revolução e instauração de uma ditadura do proletariado. A identificação do paradoxo típico das sociedades de capitalismo tardio, segundo o qual cidadãos apolíticos são formados no interior de uma sociedade repolitizada, irá acompanhar Habermas em boa parte de sua trajetória .

Para evitar confusões, é importante lembrar que aí Habermas se vale de um conceito ambíguo de política. A sociedade em si é política na medida em que o Estado, enquanto administração, intervém na sociedade civil e passa a desenvolver uma relação de interdependência no que diz respeito a ela. No entanto, a questão é justamente que a política não deve se resumir à administração. É como se tivéssemos, sob o capitalismo, uma repolitização "parcial" da sociedade. Um outro aspecto da política, o da participação popular e democrática, já incluso nas promessas do funda-

\footnotetext{
9 "Sociologicamente, determina-se o grau desta liberdade na medida em que uma sociedade utiliza os meios adquiridos da libertação das necessidades, na medida em que ela emprega as suas forças produtivas materiais e intelectuais em função do interesse de todos os indivíduos, e não apenas em função de interesses particulares. Politicamente, determina-se o grau desta liberdade na medida em que uma sociedade se torna de tal modo uma sociedade política, que a dominação é reduzida à autoridade racional, isto é, à divisão de trabalho e de experiência tanto no interesse quanto sob o controle de todos os indivíduos; ou seja, na medida em que ela consegue superar a separação entre dominação política e reprodução aparentemente privada da vida" (HABERMAS et. al. 1961, p. 55).

${ }^{10}$ Reconhecendo que há uma tensão entre duas ideias de emancipação em Marx, Benhabib chama o objetivo de realizar a ideia de liberdade e democracia presente nas instituições liberaisburguesas de "universalização do politico", que se opõe assim à "socialização do universal", que pressupunha uma transfiguração radical das instituições bem como o fim do Estado (BENHABIB 1986, p. 60). Por outro lado, Habermas não só reconhece que já há em Marx o ideal normativo de uma dominação prática (e não apenas técnica) dos processos sociais, de modo que os homens passariam a fazer a história com consciência e vontade, mas também pretende realizar esse objetivo introduzindo a ideia de uma discussão pública sem restrições, que seria possível após o pleno desenvolvimento do potencial de racionalização prática do quadro institucional (HABERMAS 1968, p. 96-8).
} 
mento legitimatório da sociedade burguesa, permanece precisamente na forma de um ideal, isto é, sem efetiva institucionalização. A solução deste problema, que bloqueia estruturalmente a participação das massas na formação da vontade política, receberá diferentes versões segundo cada tentativa empreendida por Habermas ao longo de seu percurso intelectual. É importante notar, no entanto, que em 1961, qualquer tentativa de solução passa pelo questionamento do sistema capitalista enquanto tal. Ou seja, ainda que não fale mais nos termos de uma revolução armada ou de uma ditadura do proletariado mas sim num processo plural e democrático de formação da vontade política, o conceito de emancipação concebido por Habermas ainda se aproxima daquele que foi elaborado pela tradição marxista clássica pelo menos em um ponto: trata-se de superar o modo capitalista de organização social. Por outro lado, ele se diferencia na medida em que visa evitar as perversões de uma dominação política burocratizada, tal como ocorreu nas sociedades de "socialismo real". Assim, o diagnóstico do bloqueio estrutural dos potenciais de efetivação democrática só fazem sentido quando são vistos como intimamente atrelados à manutenção da ordem privada de apropriação dos meios de produção. É exatamente porque o Estado intervém na sociedade civil a fim de manter o sistema de pé, que essa intervenção precisa ser protegida da participação popular. Como vimos, as decisões que eram tomadas no capitalismo liberal de maneira não-pública por grupos dominantes devem determinar hoje imediatamente a esfera política. Em outras palavras, as medida tomadas pelo Estado intervencionista sofrem a influência dos interesses de grupos particulares dominantes, de sorte que o poder social e econômico é atualmente eo ipso político. Em resu- 
mo, a despolitização das massas assume a forma de um fenômeno produzido a fim de assegurar que as intervenções do poder político na sociedade civil serão feitas de acordo com as prerrogativas da ordem privada de acumulação e dos interesses dos grupos particulares dominantes .

Essa posição claramente anticapitalista será revista nos anos 80, quando Habermas passa a não mais visar a supressão da economia de mercado, mas tão somente o seu controle, na medida em que esta deve permanecer dentro dos limites do sistema e não invadir e colonizar domínios do mundo da vida (HABERMAS 1981). Sendo assim, se pudemos afirmar com Pinzani (2009, p. 39) que " na introdução ao livro (...) Habermas enfrenta, pela primeira vez, a questão da participação política e apresenta uma concepção de democracia e de Estado burguês de direito que basicamente permanecerá sem grandes variações nos traços fundamentais até a publicação de Direito e Democracia", acreditamos que ao menos no ponto fundamental da critica ao capitalismo essa concepção sofrerá sensíveis modificações .

Mas se Habermas esboça já em 1961 um diagnóstico do capitalismo tardio regulado por um Estado social, assim como indica as novas tarefas de uma Teoria Critica da sociedade, falta ainda uma teoria social mais desenvolvida que deve apoiar o novo modelo crítico. É apenas a partir de Técnica e Ciência como Ideologia (1968) que o filósofo alemão começa a elaborar de maneira mais sistemática sua teoria dualista da sociedade, o que culminará com as teses desenvolvidas na Teoria da Ação Comunicativa (1981). 


\section{CONSIDERAÇÕES FINAIS}

Esperamos ter mostrado como Student und Politik é uma obra relevante para a compreensão da formação da experiência intelectual de Habermas. Ali já estão presentes muitas teses e intuições que serão desenvolvidas posteriormente em obras de maior fôlego. Claro que em 1961 elas aparecem de modo ainda bastante embrionário, e nem todos os caminhos estão traçados. Por outro lado, nem tudo será retomado nas obras de maturidade (a partir dos anos 80), sobretudo a radicalidade da crítica à sociedade capitalista. Nos anos 60, é importante insistir que Habermas mantém ainda no horizonte a perspectiva de superação da ordem capitalista, mesmo que a esse respeito ele não dê muitas indicações mais concretas.

Além disso, vimos como parte da originalidade e das diferenças que marcam a passagem da primeira para a segunda geração da Teoria Crítica pode ser compreendida tendo em vista a temática em torno do diagnóstico do capitalismo tardio, sem contudo negar certas linhas de continuidade com o modelo desenvolvido na Dialética do Esclarecimento.

Abstract: In this article, we intend to show how Habermas's intellectual project began to take shape since its first book (Student und Politik, 1961). In this work sharp differences already appear in relation to the first generation of Critical Theory, especially when it comes to the diagnosis of late capitalism. Thus, we hope to recover the importance of the work and the subject to the understanding of the theoretical trajectory of the author. Moreover, at this point Habermas still maintains a posture of radical critique of the capitalist order, which will be clearly reviewed in the works of maturity, particularly from the 80 s.

Keywords: Critical Theory; Habermas; Late Capitalism; Social Philosophy.

\section{REFERÊNCIAS}

ADORNO, T; HORKHEIMER, M. Dialektik der Aufklä- 
rung. In: ADORNO, T. W., Gesammelte Schriften 3. Frankfurt: Suhrkamp, 1997.

ADORNO, T. Spätkapitalismus oder Industriegesellschaft? In: ADORNO, T. W., Gesammelte Schriften 8. Frankfurt: Suhrkamp, 1997.

BENHABIB, S. Critique, Norm and Utopia. New York: Columbia University Press, 1986

HABERMAS, J. ; FRIEDEBURG L. v. ; OEHLER, Ch. ; WELTZ, F. Student und Politik: Eine soziologische Untersuchung zum politischen Bewusstsein Frankfurter Studenten. Neuwied: Hermann Luchterhand Verlag, 1961.

HABERMAS, J., Technik und Wissenschaft als "Ideologie”. Frankfurt: Suhrkamp, 1968.

. Kultur und Kritik. Frankfurt: Suhrkamp, 1973 .

- Theorie des kommunikativen Handelns. Dois tomos. Frankfurt: Suhrkamp, 1981.

HONNETH, A, Kritik der Macht: Reflexionsstufen einer kritischen Gesellschaftstheorie. Frankfurt: Suhrkamp, 1986 .

- Teoria Crítica. In: GIDDENS, TURNER (org.) Teoria Social Hoje. São Paulo: Editora da UNESP, 1999. MELO, R. S. Sentidos da Emancipação: Para além da antinomia revolução versus reforma. $221 \mathrm{f}$. Tese (Doutorado em Filosofia) - Faculdade de Filosofia, Letras e Ciências Humanas, Universidade de São Paulo, São Paulo, 2009.

NOBRE, M. A Dialética Negativa de Theodor W. Ador- 
no: A Ontologia do Estado Falso. São Paulo: Iluminuras, 1998 .

- Max Horkheimer: A teoria crítica entre o Nazismo e o Capitalismo Tardio. Curso Livre de Teoria Crítica. Campinas: Papirus, 2008.

PINZANI, A. Habermas. Porto Alegre: Artmed, 2009.

POLLOCK, F. State Capitalism: Its Possibilities ans Limitations. In: ARATO, A. The Essential Frankfurt School Reader. Oxford: Blackwell. 1978.

RUGSTIKY, F. Friedrich Pollock: Limites e Possibilidades. In: NOBRE, $M$ (org.). Curso Livre de Teoria Crítica. Campinas: Papirus, 2008. 